\title{
EXPERT Generating humoral immune REVIEWS \\ memory following infection or vaccination
}

Expert Rev. Vaccines 9(9), 1083-1093 (2010)

\section{Katrina L Randall \\ Department of Immunology, The Canberra Hospital and John Curtin School of Medical Research, The Australian National University, Canberra, ACT, Australia \\ Corresponding Address: Department of Immunology, The Canberra Hospital, PO Box 11 Woden ACT 2606, Australia Tel.: +61 261745282 Fax: +61 262442892 katrina.randall@anu.edu.au}

The production of long-lived, high-affinity antibodies forms the basis of many successful vaccination strategies. Although much is known of the proteins and pathways of the immune system that lead to the production of these antibodies, there are also many processes that remain unexplained or poorly explained. Some vaccines and infections lead to life-long protection while others elicit poor immune responses. Understanding the processes that lead to effective antibody production will allow us to recognize what aspects of the function of the immune system are subverted or compromised in the situation of ineffective vaccines and chronic persisting infection. This article will discuss the latest research into the mechanisms, pathways and proteins important for the production of long-lived humoral immunity, with a particular emphasis on the role of the germinal center, and how this research may be harnessed in the search for more effective vaccines and vaccination strategies.

KeYwoRDs: follicular dendritic cell $\bullet$ germinal center $\bullet$ memory $\bullet$ primary immunodeficiency $\bullet$ T-follicular helper cell - vaccination

\section{Mechanisms of}

\section{antibody-induced immunity}

The word immunity is derived from the Latin immunitas (protection from taxes) and was used to describe the protection from disease for anyone who had previously survived infection with the same disease - a phenomenon first described by Thucydides in $430 \mathrm{BC}$, when he noted that those who survived the plague were not struck again [1].

Peter Ludwig Panum also described lifelong protection to a particular infection, while helping during a measles outbreak in the Faroe Islands in 1846. He noted that the virus had infected all age groups on the island, rather than just the children who were usually susceptible. Those aged over 65 years of age, however, were protected and he noted that it had been exactly 65 years since measles had last been seen in the Faroe Islands [201]. Those who had survived the outbreak at that time were still protected, by what we now know are long-lived antibody responses.

A compelling insight into the longevity of specific antibody production has come from analysis of serum from people who survived the 1918 influenza pandemic. These survivors still have high-affinity antibodies despite no exposure since that time [2]. Memory B cells making antibodies against the 1918 pandemic influenza strain could be isolated from these individuals at least 70 years after the last encounter with a serologically reactive strain of the virus, and these antibodies bound the 1918 influenza hemagglutinin with extraordinarily high affinity.

High-affinity, long-lived antibody production is the basis for all successful vaccines. Edward Jenner noted in the 1790s that milk maids previously infected with the more benign cow pox were protected from small pox and this formed the bases of the first immunizations [1]. It is now known that antibody responses are maintained for 75 years after smallpox immunization [3], and vaccination-induced antibodies have been shown in an animal model to be necessary and sufficient for protection against lethal monkey pox infection [3].

Why do some infections and vaccinations not produce long-lived antibodies? What is it about the immune reaction that is caused by some immunizations that gives rise to life-long immunity to disease that differs in immunizations that need to be boosted or provide very little immunity at all? What is known about the mechanisms, proteins and pathways behind the production of long-lived antibody responses? This article will discuss the current knowledge 
of the formation of germinal center (GC) and the genes and proteins that have been shown to be essential for this process. Some of these questions can be answered but much still remains to be discovered.

\section{T-cell-dependent immune responses}

The normal immune response is characterized by a primary phase of production of IgM and then IgG antibodies by plasma cells formed from the terminal differentiation of $\mathrm{B}$ cells, a few days after the initial encounter with antigen, and in most cases this, usually together with activation of both CD4 and CD8 T cells, allows for the antigen to be cleared. A feature of the immune system in higher vertebrates is that memory of this encounter is manifest if the antigen is encountered again. The recall (secondary) response is faster, yields higher titers of antibody, is usually dominated by class-switched IgG antibody and is of higher affinity. It is the recall response that forms the basis for vaccination.

The cells responsible for the secondary response are memory $\mathrm{B}$ cells and long-lived bone marrow plasma cells $[4,5]$. These cells are the product of GCs produced during the primary response to a T-cell-dependent antigen. GCs can form in response to T-independent antigens but they are short lived and seem to disappear without the formation of long-term memory cells [6]. By contrast, GCs produced in response to T-cell-dependent antigens persist for at least 3 weeks and produce both memory B cells and long-lived plasma cells with higher affinity B-cell receptors (BCRs) due to the process of affinity maturation and positive selection, which occurs in the GC $[4,7,8]$, as will be discussed later. It used to be thought that $\mathrm{T}$-cell help would be required for class switching of antibody as well as GC formation, but it is now known that the $\mathrm{CD} 40$ receptor on $\mathrm{B}$ cells required for class switching can be bound by C4BP (a complement protein), as well as its classical ligand on T cells, CD40L (CD154) [9]. Thus, class-switched antibody can be seen during a T-cell-independent immune response.

There is also now some evidence that the formation of memory B cells can occur independently of the formation of GCs, and also in response to T-independent antigens, but that the memory $\mathrm{B}$ cells formed in this way are different to those produced by the classical pathway $[10,11]$. In mice in which no GCs can be formed, or in those manipulated to disrupt GC formation, memory B cells with low, rather than high, affinity for the antigen were produced [11]. Memory B cells were also detected in mice immunized with T-independent antigen NP-Ficoll - they were found to be long lasting and to have a distinct set of cell surface markers [10]. Early memory B cells that occur before GC formation are also seen early in the T-cell-dependent immune response [12].

A population of memory $\mathrm{B}$ cells has also been found in humans who, owing to genetic defects, cannot mount a classical T-celldependent immune response. These cells have been found to be circulating splenic marginal zone $\mathrm{B}$ cells, specifically produced to allow a rapid response to bacteria with polysaccharide capsules. They carry a diversified antigen receptor repertoire that is thought to diversify before antigenic challenge [13].

In this article, however, I will focus on T-cell-dependent immune responses and their associated GC reactions.
T-cell-dependent antibody responses occur after antigen-specific $\mathrm{B}$ and $\mathrm{T}$ cells interact at the T-B border of the lymphoid follicle. The $\mathrm{B}$ cells, thus activated, can undergo one of two fates $[7,8]$ :

- Differentiation into plasmablasts that accumulate in the bridging channels between the $T$ zones and red pulp of the spleen or the medullary cords of the lymph node. These extrafollicular plasmablasts undergo proliferation and terminal differentiation to become short-lived plasma cells that secrete antibodies against the antigen that activated both the $\mathrm{B}$ and $\mathrm{T}$ cells. The first production of antibodies to the invading antigen is from this extrafollicular plasma cell response;

- Movement into the follicle where they establish GCs. GCs are areas of proliferating $\mathrm{B}$ lymphocytes within the primary follicle. They can be distinguished histologically 3-5 days after the activated B cells first move into the follicle.

The exact mechanism that governs which choice the $\mathrm{B}$ cell makes after receiving the T-cell stimulus is still not known. There was some experimental evidence that it was the affinity of the BCR for the cognate antigen that determined the pathway taken. Transferring cells with transgenic receptors for the antigen hen egg lysozyme (HEL) into mice immunized with sheep red blood cells and either wild-type HEL, to which the cells would have high affinity, or HEL ${ }^{3 \mathrm{X}}$, a mutated protein to which the cells would have greater than 10,000-lower binding affinity, Phan et al. showed that immunizing with high-affinity antigen led to both extrafollicular and GC formation, while immunizing with lowaffinity antigen led to GC formation only [14], while other studies had shown preferential recruitment of high-affinity cells to the GC reaction [15]. More recently, Chan et al. have shown that it was not the fate decision that was determined by the affinity of the antigen but rather the degree of extrafollicular expansion that occurred [12]. Low-affinity antigen led to markedly less extrafollicular expansion, and the predominant populations of antigenreactive cells were, therefore, in the GC. Proliferation in response to low-affinity antigen was slightly reduced, but apoptosis was markedly increased in the situation of low-affinity antigen [12]. A similar phenomenon of differential apoptosis rates has recently been reported to occur in the GC as well [16].

Studies of Salmonella infection in mice have shown that the choice between the extrafollicular response and the formation of GCs may also be related to antigen burden. Cunningham et al. have shown that the immune response to Salmonella in mice is characterized by an exclusive extrafollicular response of $\operatorname{IgM}$ and IgG2c antibodies for the first month, and that GC formation is delayed, as is the affinity maturation of the immune response [17]. This extrafollicular reaction was, however, T-cell dependent. The formation of GCs occurred earlier when antibiotics were used to decrease the bacterial burden [17].

It has recently been found that it is the expression of the orphan G-coupled receptor EBI2 that directs the fate of the B cell as either follicular or extrafollicular. Activated B cells expressing normal levels of EBI2 move into the extrafollicular areas, whereas B cells that downregulate EBI2 become GC B cells [18,19]. It is not known, however, how this EBI2 receptor expression is controlled. 
Autoreactive $\mathrm{B}$ cells are also known to be excluded from becoming follicular and, subsequently, GC B cells in a process known as follicular exclusion. In a number of mouse models of autoimmunity, the self-reactive B cells are seen to accumulate at the $\mathrm{B}-\mathrm{T}$ interface. This process has been shown to be dependent on the expression of FcyRIIb [20], but the exact mechanisms of this exclusion remain elusive.

\section{GCs as factories of long-lived immunity}

As reviewed by Nieuwenhuis and Opstelten, GCs were first described in 1884 by Flemming, who thought that they represented the source of all lymphocytes in the circulation [7,21]. This was later contested by Hellman, who felt that the GCs, which changed in shape and size, were an unlikely constant source of lymphocytes and instead felt that the GCs should be known as reactive centers. Glimstedt found that germ-free guinea pigs did not have GCs but did have a normal numbers of lymphocytes. It was later described that GCs represented proliferating B cells within secondary lymphoid tissues [21].

As described previously, activated B cells destined to form GCs first move to the center of the B-cell follicles and proliferate within a network of nonphagocytic dendritic cells known as follicular dendritic cells (FDCs) [7]. As the GC grows, two different compartments can be discerned - the light zone and dark zone - named for their histological appearance. Chemokines are important for positioning of cells in the light and dark zone, with chemokine receptor (CXCR) 4 and CXCR5 and their ligands important for maintaining the separation of the two zones [22]. Also known to be present in the GC are specialized T cells, known as T-follicular helper cells. The cellular components of the GC and recent insights into their function will be discussed further in the next section.

The observation that the antibody response to antigen improved during an immune response was first noted more than 70 years ago [23]. This was found to be dependent on the amount of antigen present [24] and found to be due to changes within the antibody [25]. This process was termed affinity maturation of the immune response [26].

Affinity maturation was later found to be due to selection of cells with amino acid substitutions within the variable regions of the immunoglobulin molecule. This somatic hypermutation of the immunoglobulin molecule was found to be characteristic of antibodies produced by long-lived plasma cells and memory $\mathrm{B}$ cells $[4,7,8,27]$. As the process of somatic hypermutation was occurring at the same time as the formation of GCs, it was long suspected that the process of somatic hypermutation occurred within GCs [27,28]. In breakthrough studies in 1991, characterization of individual cells from the GC showed that they indeed carried multiple mutations with evidence of clonality amongst surrounding cells and similar mutations indicating a stepwise process of acquiring mutations [29,30], thus confirming that the process of somatic mutation occurred in the GC. Affinity maturation is therefore the selection of B cells for which somatic hypermutation has brought about a favorable increase in binding affinity for the triggering antigen, and this selection is also thought to occur within the GC. The process of affinity maturation is not completely dependent on the presence of GCs, as it has been shown to occur in mice in which proper GCs do not form in response to particular types of immunization [31], but it is likely that GCs have arisen as a specialized environment to support efficient affinity maturation $[4,7,8]$.

The exact mechanism by which the selection of higher affinity clones occurs is yet to be determined. Although much has been learnt about the cells and cellular interactions of the GC, there is still controversy about the relative importance of each of the cellular components in the process of selection and affinity maturation. High- and low-affinity B cells compete with one another for survival signals - possibly from direct interaction with antigen on the FDC, or perhaps enhanced antigen capture, presentation and T-cell help [32].

Recent insights will be discussed together with relevant mouse models in the next section.

\section{Cells of the GC}

In the classical representation of the events of the GC, B cells activated by $\mathrm{T}$ cells enter the $\mathrm{B}$-cell follicle and proliferate. As they proliferate they are known as centroblasts and are predominantly found in the dark zone of the GC. These cells rapidly divide and undergo somatic hypermutation. They then re-express their surface BCR and enter the light zone to become centrocytes, where they check their new BCR for higher affinity to the antigen attached on FDCs as immune complexes. Centrocytes that fail to bind to the antigen undergo apoptosis [33]. These events are illustrated in Figure 1.

Visualizing these events with two-photon microscopy has revealed that, although this sequence of events remains essentially correct, it is also more complicated. It has now been shown that there are dividing cells in both the light and dark zones, rather than them being exclusively in the dark zone, and that the cell migration is more complex than previously thought. Cells were found to move in both directions, and cell division and cell death occurred in both compartments, although there were far fewer dividing cells in the light zone [34-36]. The mechanism of selection of GC B cells is still controversial. In the classical GC model, GC B cells with the appropriately mutated BCR were selected on antigen-bearing FDCs in the light zone. Recent insights with two-photon microscopy and other experiments have suggested that selection could occur in both the light and dark zones [7]. FDCs are known to be present in both the light and dark zones, with the light zone FDCs capable of trapping more antigen [37]. The light zone also contains more $T$ cells. As will be discussed in more detail in subsequent sections, there is now evidence that both FDCs and follicular $\mathrm{T}$ cells are likely to play a role in the selection of high-affinity GC B cells [7].

As discussed previously, interactions between $\mathrm{B}$ and $\mathrm{T}$ cells are vital for the formation and persistence of GCs. No GCs are formed in mice lacking molecules important for this initial B-T-cell interaction. A detailed discussion of each molecular defect in mice that leads to failure of GC formation or their persistence is beyond the scope of this article, but the main defects are classified according 


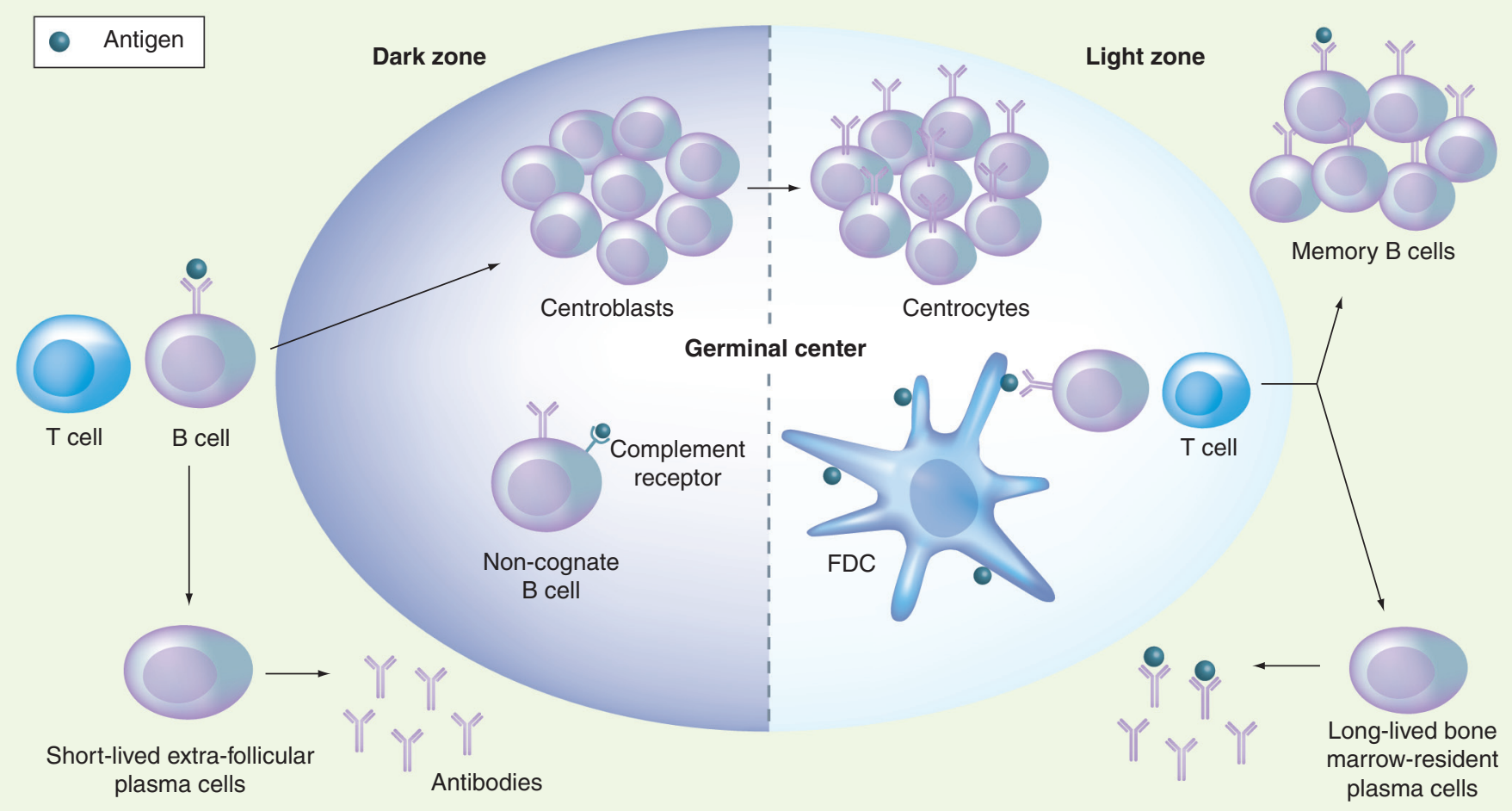

Figure 1. Events of the T-dependent immune response. Cognate B and T cells interact at the T-B border in secondary lymphoid tissue. B cells, thus activated, either become short-lived extrafollicular plasma cells or enter the follicle and proliferate to form the germinal center. Antigen can be brought to the germinal center by noncognate B cells. Proliferating B cells in the dark zone of the germinal center are known as centroblasts and B cells expressing their B-cell receptor in the light zone are known as centrocytes. B cells that successfully mutate their B-cell receptor to give higher affinity to the antigen get survival signals from FDCs and T follicular helper cells, allowing them to survive and differentiate into memory B cells or long-lived plasma cells.

FDC: Follicular dendritic cell.

to mechanism and listed in Table 1. Also important for GC B-cell formation and persistence are B-cell intrinsic signals. GC B cells have high levels of the transcription factor Bcl- 6 and mice lacking Bcl-6 have no GCs [38]. Mice in which there is a failure of proper BCR signaling also have abnormalities in GC formation and persistence (TaвLE 1$)$.

The FDCs capture and retain antigen in the form of immune complexes on their surface and this is thought to play a vital part in selection of B cells (centrocytes) carrying high-affinity BCRs [39]. As reviewed by Allen and Cyster, FDCs are of mesenchymal origin [37] and their formation is dependent on NF-KB signaling $[40,41]$. Their formation is also dependent on lymphotoxin (LT) $\alpha$ and TNF production by bone marrow-derived $B$ cells [42-44]. Mice with defects in these molecules lack FDC and have absent GCs (TABLE 1).

As described previously, the classical model of GC B-cell selection relies on selection of $\mathrm{B}$ cells, with high-affinity $\mathrm{BCR}$ s binding to antigen in the form of immune complexes held on the surface of FDC on complement and FcR receptors. This aspect of GC $\mathrm{B}$-cell survival is controversial. A transgenic mouse developed with surface but not circulating antibodies was found to have GCs and some evidence of affinity maturation, despite having no detectable immune complexes on the FDC [45]. This may be due to the presence of secreted antibody, below the level of detection, or due to complement proteins substituting for secreted immunoglobulin in the formation of immune complexes. However, two-photon microscopy has shown that GC B cells travel rapidly over FDCs and do not seem to be firmly adherent to them [7]. Other work, however, supports the important role of immune complex deposition on FDCs in germinal B-cell survival - in $\mathrm{BAFF}^{-1-}$ mice, GCs form but cannot persist, and these mice have been found to have absent immune complex deposition on their FDCs [46]. In addition, disrupting the delivery of immune complexes to FDCs was found to affect proper affinity maturation of the immune response [47].

To distinguish between FDCs present in the B-cell follicle and those present in a GC, the two types are commonly described as primary and secondary, respectively. The exact nature of the signals involved in transition from primary to secondary FDCs are unknown, but it is proposed that further TNF and LT signaling is required [37]. Secondary FDCs differ from primary FDCs in their expression of integrin ligands, such as VCAM-1 or ICAM-1 [37], and by their increased expression of Fc $\gamma$ RIIb receptors, and can present antigen on both complement and Fc $\gamma$ RIIb receptors. The presence of ICAM-1 and VCAM-1 on FDCs has been shown to be important for GC B-cell persistence. Mice engineered so that the I- $\mathrm{KB}$ kinase $\beta$ (IKK2) gene was inactivated only in FDCs are unable to express VCAM-1 and ICAM-1 on the surface of the FDCs, and this resulted in the formation of smaller GCs with 
a greater number of apoptotic cells. This also led to a reduced antibody response to immunization [48]. Dedicator of cytokinesis 8 (DOCK8)-deficient mice have been found to have a defect in immune synapse formation upon antigen stimulation with membrane-bound antigen, with an inability to cluster LFA-1 and interact with ICAM-1. These mice were also found to have an intrinsic cell defect in GC formation and persistence [49].

Recent research has found that one important way for antigen to get to the GC is transportation by noncognate $\mathrm{B}$ cells. Subcapsular macrophages were found to trap antigen in the form of immune complexes [50] and these antigens could then be transported to the GC reaction by both cognate and noncognate $\mathrm{B}$ cells [50]. Noncognate $\mathrm{B}$ cells transport the antigen on their complement receptors and disrupting this process was shown to affect affinity maturation [47].

There is also evidence that specialized $\mathrm{T}$ cells within the GC can provide survival and selection signals for GC B cells $[4,51,52]$. These specialized $\mathrm{T}$ cells are also known as T-follicular helper (TFH) cells. They are characterized by expression of the cell surface markers CXCR5 and inducible costimulator (ICOS), and upregulate the expression of CD40L and OX40 when activated [53].

Recently, it has been shown that expression of the transcription factor Bcl-6 is essential for TFH cell formation, in addition to GC B-cell formation, and that expression of this transcription factor increases the surface expression of CXCR5, as well as other characteristic surface markers of TFH cells, including PD-1 and CXCR4 [54-56].

IL-21, an important cytokine produced by $\mathrm{T}$ cells in the GC, has been found to have important effects on GC B-cell persistence. Two groups have found that lack of IL-21 signaling in B cells led to a more rapid dissolution of the GC [57,58], as IL-21 signaling was important to maintain $\mathrm{Bcl}-6$ expression in GC B cells.

Follicular dendritic cell and T-cell signals both seem to be important for GC B-cell selection and affinity maturation, but the relative importance of each is yet to be determined. Only a small number of GC B cells are destined to survive and they are selected because they have a higher affinity receptor for the immunizing or infecting antigen.

Molecule

affected

CD28

CD80, CD86 $N F-\kappa B 2$, RelB

BAFF

GANP

Other

DRAK2

BAFF-R

\section{Table 1. Known or proposed mechanisms for interfering with germinal center formation.}

Outcome

Act as B-cell transcription factors

Bcl6 Failure of GC formation [38]

IRF8 Decreased Bcl6 expression, disordered GC

OBF-1, Oct2 Failure of GC formation

Act in B-cell signaling

$\begin{array}{lll}\text { CD45 } & \text { Failure of GC B-cell persistence } & {[93]} \\ \text { DOCK8 } & \text { Failure of GC B-cell persistence } & {[49]} \\ \text { PI3K } 8 & \text { Failure of GC formation } & {[94]} \\ \text { CD19 } & \text { Failure of GC formation } & {[95]} \\ \text { SWAP70 } & \text { Smaller and fewer GCs } & {[96]} \\ \text { SPI-B } & \text { Smaller GC and failure to persist } & {[97]} \\ \text { TC21 } & \text { Smaller GC and failure to persist } & {[98]}\end{array}$

Act in $B-T$ interactions

SAP Failure of GC formation

Failure of GC formation

Failure of GC formation

[100]

CD40, CD40L Failure of GC formation

[101,102]

ICOS, ICOSL Failure of GC formation

Failure of GC formation

Act in FDC formation and function

LTa, TNF, TNFR1, Failure of FDC formation, failure of GC formation

$[40,41,104,105]$

IKK2 $2^{\mathrm{FDC}} \quad$ Smaller GCS, more apoptosis

[48]

Failure of GC persistence

[46]

Act as DNA-modifying enzymes

Msh2 Smaller GC, more apoptosis and failure to persist

Delayed GC formation, increased apoptosis

[107]

mIR-155

Fewer GCs

[108]

Fewer GCs, more apoptosis

Lack of IL-21 signaling in B cells led to failure of

$$
\text { Failure of GC persistence }
$$

BAFF: B-cell-activating factor; BAFF-R: B-cell-activating factor receptor; CD4OL: CD40 ligand; DRAK: Deathassociated protein-related apoptopic kinase; FDC: Follicular dendritic cell; GC: Germinal center;

ICOS: Inducible costimulator; ICOSL: Inducible costimulator ligand; SAP: Signaling lymphocyte activation molecule-associated protein.

Germinal center B cells that undergo affinity maturation and selection within the GC become either long-lived bone marrowresident plasma cells or memory B cells. The mechanisms that lead to the formation of these cell types and how the choice is made by individual cells are not fully understood. It is known 
that differentiation to become a plasma cell requires a BCR of high affinity, while memory $\mathrm{B}$ cells are produced as long as the cell survives [8,59]. In the context of a normal GC, such survival is, of course, also dependent on having a high-affinity receptor. This difference in requirements was found in studies of Bcl-2 transgenic mice - in which antiapoptotic signals overcame the usual apoptosis of the GC B cells. Only plasma cells with highaffinity receptors were produced, while the memory compartment consisted of both high- and low-affinity cells $[8,59]$.

It is also known that when the transcription factor IRF4 is conditionally deleted in GC B cells, plasma cells and plasmablasts are not formed [60] and the transcription factors Blimp-1 and XBP-1 are also important in plasma cell formation $[61,62]$.

\section{Human immune deficiencies affecting GC formation}

How can these basic insights into the GC using genetically modified mice help us to improve human vaccination? Rare human monogenic immunodeficiencies confirm that these mechanisms are also important in the human immune response to infection.

Patients with hyper IgM syndromes are susceptible to recurrent bacterial infections of the respiratory and GI tracts. The prototype for this group of disorders is X-linked hyper-IgM syndrome (hyper IgM type 1; HIGM1) caused by inactivating mutations in the protein CD 40L [63-66]. In addition to sinopulmonary bacterial infections, these individuals are also susceptible to infections usually associated with T-cell deficiency, such as Pneumocystis jiroveci. Interaction between the CD40L receptor, CD40, on $\mathrm{B}$ cells and CD40L on T cells is vital for proper B-T-cell interactions and type 1 autosomal recessive hyper-IgM (hyper-IgM syndrome 3) results from inherited defects in CD 40 [67]. Patients with these types of hyper-IgM syndromes cannot make GCs, and class-switch recombination and somatic hypermutation of the antibody genes is severely diminished. As the name suggests, patients with hyper-IgM syndromes have normal or elevated IgM levels but no antibodies of other classes, despite normal numbers of $\mathrm{B}$ and $\mathrm{T}$ cells.

The absence of the SAP protein in humans leads to the disease X-linked lymphoproliferative disease (XLP) or Duncan's disease [68-70]. SLAM-associated protein (SAP) has been shown in mouse studies to be important for GC formation [71]. Like the interactions described previously, this defect was also found to be due to abnormal B-T-cell interactions [72] in the mouse model. Patients with XLP have a dysregulated response to infection with Epstein-Barr virus (EBV), a $\gamma$ herpes virus that invades B cells and is fatal within 1-2 weeks in the majority of XLP sufferers who develop fulminant infection. Those who survive the EBV infection develop hypogammaglobulinemia, lymphoma or continued lymphoproliferation [73]. These features have also been found in patients who have not been infected with EBV and so, while part of the pathogenesis of the disease is an abnormal response to EBV infection, there are also other defects in the immune system, including impaired production of memory B cells and long-lived plasma cells, as well as a deficiency of natural killer (NK) T cells [73,74]. Their CD4 and CD8 T cells show impaired function, as do their NK cells $[73,74]$.
The most common, clinically significant, primary immunodeficiency is common variable immunodeficiency (CVID). CVID denotes a group of heterogeneous conditions characterized by increased susceptibility to bacterial infections, particularly sinopulmonary infections, variable hypogammaglobulinemia and poor vaccine responses. The majority of cases are sporadic, but in $10-20 \%$ of cases familial inheritance is seen [75].

The first monogenic cause of CVID to be found was ICOS deficiency [76]. ICOS is a cell surface molecule induced on activated $\mathrm{T}$ cells that binds to ICOSL on B cells providing co-stimulatory signals. Patients lacking ICOS were found to have decreased IgG levels, decreased memory and naive $\mathrm{B}$ cells, and recurrent bacterial infections [76]. Secretion of IL-10 and IL-17 was impaired and there was impaired production of GCs [77]. ICOS is, therefore, important in humans for late B-cell differentiation, class switching, immunoglobulin and memory B-cell production. In mice, by contrast, ICOS deficiency leads to a complete failure of $\mathrm{GC}$ formation and a phenotype closer to mice lacking CD 40 or CD40L [78].

Mutations in the B-cell antigen signaling protein CD19 have also been found in four people with CVID (three from the same family) - all presented in childhood with recurrent bacterial infections and were identified as having hypogammaglobulinemia. The mutations resulted in premature stop codons within the cytoplasmic tail segment, decreased or led to undetectable CD19 expression on the cell surface and defective CD19 signaling and calcium flux. GC formation appeared to be grossly normal and hypermutation was evident in the immunoglobulin transcripts from the small number of $\mathrm{CD} 27^{+}$cells present. The primary and especially the recall titers and avidity of antibody to rabies vaccine were decreased, and there were markedly decreased IgD- (switched) $\mathrm{CD} 27^{+}$memory B cells [79]. In mice, complete CD19 deficiency, as noted in TaвLe 1 , is associated with complete absence of GC formation, but mice in which the PI-3-binding domain of CD19 only is mutated, form GCs that cannot persist [80]. The most recent gene defect found in a patient with CVID is a homozygous mutation in CD81, one of the other proteins essential for the cell surface expression of CD19 [81]. The presence or absence of GCs in this patient has not been established.

Follicular and marginal zone B cells depend upon a circulating and membrane-bound protein of the TNF family, BAFF, for their survival. BAFF binds to three different cell surface receptors-TACI, BCMA and BAFF-R. In addition, APRIL, a related member of the TNF family, also binds to the TACI and BCMA receptors [82].

A group of patients with CVID and selective IgA deficiency (the most common primary immunodeficiency) have been found to have mutations in the TNFRSF13B gene encoding TACI [83,84]. Homozygous, compound heterozygous and heterozygous mutations were identified. The clinical significance of heterozygous mutations affecting TACI remains elusive as heterozygous mutations have also been identified in the normal population, with some heterozygous mutations more frequent in CVID and some mutations occurring at the same rate in CVID and in the normal population [85]. Mice deficient for TACI show GC formation with evidence of lymphoproliferation and autoimmunity [86]. Patients with CVID can also present with autoimmunity [83]. 
More recently, homozygous twins were described who both had a defect in the TNFRSF13C gene encoding BAFF-R - while both had decreased numbers of mature $B$ cells and low $\operatorname{IgG}$ and $\operatorname{IgM}$ (but normal IgA) levels, and had abnormal vaccine responses, only one of the twins had recurrent infections [87]. Mice with BAFF-R mutations can initiate GCs but they cannot persist [46].

While only a small number of people have these genetic defects, it may be that polymorphisms or heterozygous mutations in these proteins and other proteins important in the GC are responsible for the variations in vaccine responsiveness that we see. Research into GC formation will allow a better understanding of how these polymorphisms may manifest in the general population.

\section{GCs \& vaccination strategies}

How can the immune response be directed to ensure a GC response after vaccination?

The basic knowledge of the cells, proteins and pathways important for GC formation and long-lived antibodies is already informing vaccine research and design. Zheng et al. found that the agerelated decrease in GC formation in mice could be overcome by immunization with preformed immune complexes rather than antigen on its own, allowing better presentation by FDC [88]. They injected nitrophenol-chicken gammaglobulin (NP-CGG) either on its own, as an immune complex, or together with an isotype control antibody and found that both young and old mice had a better primary response to the immune complex containing NP-CGG than the NP-CGG on its own, but the difference with immune complex vaccination was more marked in the older mice.

Rush et al. used a mouse model system with transgenic B and $\mathrm{T}$ cells to ensure that DNA vaccines were able to stimulate all aspects of the T-cell-dependent immune response required for proper GC formation, such as T-cell activation, migration to $\mathrm{B}$-cell areas and activation of B cells, and produce long-term, high-affinity antibody [89].

The effects of various adjuvants on GC formation have also been studied with the aim to understand how these substances improve the antibody responses after vaccination. Ma et al. used poly:IC, a Toll-like receptor (TLR)3 ligand and retinoic acid as adjuvants in studies of C57BL/ 6 mice immunized with tetanus toxoid and found that using poly:IC alone or together with retinoic acid increased GC volume and class switching to IgG1 antibodies [90].

\section{Expert commentary}

The proper formation of GCs is central to an effective humoral immune response, as both long-lived plasma cells and memory $\mathrm{B}$ cells arise in this important lymphoid structure. Although much is already known about the cells and cellular interactions that occur during this process, how selection of high-affinity cells occurs and the exact signals that govern their terminal differentiation to form long-lived plasma cells and memory B cells is yet to be elucidated.

As discussed in this article, some important insights have recently been gained into aspects of the GC, including the genetic program important for the formation of cells specific to the GC, the importance of the cytokine IL-21 and the role of noncognate $\mathrm{B}$ cells in delivering antigen to the GC reaction.
The current controversies in this area concern, in particular, defining the cells important for GC B-cell survival and affinity maturation - is this due to FDCs, TFHs or both? What are the particular pathways that allow selection of high-affinity clones of B cells specific for infections, and prevent the same affinity maturation from occurring for self-reactive clones? Do the two histologically distinct areas of the GC contain cells maturing in parallel or do the cells have to move from one zone to the other for optimum maturation? These are questions that have been studied for some time, but better visualization of the workings of the GC, and increased knowledge of the genes and mechanisms involved, are hoped to provide definite answers in the coming years. As we are able to characterize the function of various proteins known to be expressed in GC B cells, these questions will gradually be answered.

Research into monogenic causes of human humoral immunodeficiency has provided and will continue to provide important insights into the formation and function of GCs, and the human adaptive immune response.

The more we understand this important aspect of human immunity, the more we will be able to gain insights into better vaccination strategies. For example, recent insight from mouse models about antigen delivery to the GC in the form of immune complexes, the role of FDC in presenting immune complexes and the improved results when immune complexes were used as part of a vaccination strategy allow us to consider whether these strategies should be translated into human vaccination strategies.

\section{Five-year view}

While current research into human GC defects is allowing a better understanding of disease pathogenesis and classification, allowing more targeted protection from infections and raising the possibility of prenatal diagnosis, the knowledge uncovered will have more far-reaching implications in the future.

This knowledge of the cellular biology and molecular genetics of the GC could be used to harness the power of GCs and affinity maturation for the production of more effective vaccines. It is also hoped that this greater knowledge and greater availability of genetic testing will be able to predict who will have suboptimal vaccine responses and allow a tailoring of the vaccination program to achieve maximal protection.

\section{Acknowledgements}

The author would like to acknowledge the help of Professors Chris Goodnow and Carola Vinuesa in compiling this article.

\section{Financial \& competing interests disclosure}

The author has no relevant affliations or financial involvement with any organization or entity with a financial interest in or financial conflict with the subject matter or materials discussed in the manuscript. This includes employment, consultancies, honoraria, stock ownership or options, expert testimony, grants or patents received or pending, or royalties.

No funding for writing assistance was utilized in the production of this manuscript. 


\section{Key issues}

- Long-lived, high-affinity antibody responses are a product of the germinal center

- Affinity maturation of B cells occurs in the germinal center.

- Although many of the proteins and pathways important in the generation of long-term memory have been discovered, many details of how particular germinal center events occur are still not known.

- Investigation of the causes of primary humoral immunodeficiency in humans has led to discoveries in important biological processes, particularly related to germinal center formation and function.

- Variability in vaccination responses may be due to polymorphisms within the population in the proteins responsible for important aspects of germinal center function.

- Further study of the germinal center and human immunodeficiency will be important for the generation of better future vaccines.

\section{References}

Papers of special note have been highlighted as:

- of interest

1 Ahmed R, Rouse BT. Immunological memory. Immunol. Rev. 211(1), 5-7 (2006).

2 Yu X, Tsibane T, McGraw PA et al. Neutralizing antibodies derived from the B cells of 1918 influenza pandemic survivors. Nature 455(7212), 532-536 (2008).

3 Amanna IJ, Slifka MK, Crotty S. Immunity and immunological memory following smallpox vaccination. Immunol. Rev. 211, 320-337 (2006).

4 McHeyzer-Williams LJ, McHeyzer-Williams MG. Antigen-specific memory B cell development. Annu. Rev. Immunol. 23, 487-513 (2005).

5 Tarlinton D. B-cell memory: are subsets necessary? Nat. Rev. Immunol. 6(10), 785-790 (2006).

6 de Vinuesa CG, Cook MC, Ball J et al. Germinal centers without T cells. J. Exp. Med. 191(3), 485-494 (2000).

7 Allen CDC, Okada T, Cyster JG. Germinal-center organization and cellular dynamics. Immunity 27(2), 190-202 (2007).

8 Tarlinton DM. Evolution in miniature: selection, survival and distribution of antigen reactive cells in the germinal centre. Immunol. Cell Biol. 86(2), 133-138 (2008).

9 Brodeur SR, Angelini F, Bacharier LB et al. C4b-binding protein (C4BP) activates $\mathrm{B}$ cells through the $\mathrm{CD} 40$ receptor. Immunity 18(6), 837-848 (2003).

10 Obukhanych TV, Nussenzweig MC. T-independent type II immune responses generate memory B cells. J. Exp. Med. 203(2), 305-310 (2006).

11 Inamine $\mathrm{A}$, Takahashi $\mathrm{Y}, \mathrm{Baba} \mathrm{N}$ et al. Two waves of memory B-cell generation in the primary immune response. Int. Immunol. 17(5), 581-589 (2005).
12 Chan TD, Gatto D, Wood K, Camidge T, Basten A, Brink R. Antigen affinity controls rapid T-dependent antibody production by driving the expansion rather than the differentiation or extrafollicular migration of early plasmablasts. J. Immunol. 183(5), 3139-3149 (2009).

13 Weller S, Braun MC, Tan BK et al. Human blood IgM "memory" B cells are circulating splenic marginal zone B cells harboring a prediversified immunoglobulin repertoire. Blood 104(12), 3647-3654 (2004).

14 Phan TG, Paus D, Chan TD et al. High affinity germinal center $\mathrm{B}$ cells are actively selected into the plasma cell compartment. J. Exp. Med. 203(11), 2419-2424 (2006).

15 Shih T-AY, Meffre E, Roederer M, Nussenzweig MC. Role of BCR affinity in $T$ cell dependent antibody responses in vivo. Nat. Immunol. 3(6), 570-575 (2002).

16 Anderson SM, Khalil A, Uduman M et al. Taking advantage: high-affinity B cells in the germinal center have lower death rates, but similar rates of division, compared to low-affinity cells. J. Immunol. 183(11), 7314-7325 (2009).

17 Cunningham AF, Gaspal F, Serre K et al. Salmonella induces a switched antibody response without germinal centers that impedes the extracellular spread of infection. J. Immunol. 178(10), 6200-6207 (2007).

18 Gatto D, Paus D, Basten A, Mackay CR, Brink R. Guidance of B cells by the orphan $G$ protein-coupled receptor EBI2 shapes humoral immune responses. Immunity 31(2), 259-269 (2009).

19 Pereira JP, Kelly LM, Xu Y, Cyster JG. EBI2 mediates B cell segregation between the outer and centre follicle. Nature 460 (7259), 1122-1126 (2009).

20 Paul E, Nelde A, Verschoor A, Carrol MC. Follicular exclusion of autoreactive B cells requires Fc $\gamma$ RIIb. Int. Immunol. 19(4), 365-373 (2007).
21 Nieuwenhuis P, Opstelten D. Functional anatomy of germinal centers. Am. J. Anatomy 170 (3), 421-435 (1984).

22 Allen CDC, Ansel KM, Low C et al. Germinal center dark and light zone organization is mediated by CXCR 4 and CXCR5. Nat. Immunol. 5(9), 943-952 (2004).

23 Heidelberger M, Kendall FE. A quantitative theory of the precipitin reaction. III. The reaction between crystalline egg albumin and its homologous antibody. J. Exp. Med. 62(5), 697-720 (1935).

24 Eisen HN, Siskind GW. Variations in affinities of antibodies during the immune response. Biochemistry 3, 996-1008 (1964).

25 Steiner LA, Eisen HN. Sequential changes in the relative affinity of antibodies synthesized during the immune response. J. Exp. Med. 126(6), 1161-1183 (1967).

26 Siskind GW, Benacerraf B. Cell selection by antigen in the immune response. $A d v$. Immunol. 10, 1-50 (1969).

27 Liu YJ, Joshua DE, Williams GT, Smith CA, Gordon J, MacLennan IC. Mechanism of antigen-driven selection in germinal centres. Nature 342(6252), 929-931 (1989).

28 Wagner SD, Neuberger MS. Somatic hypermutation of immunoglobulin genes. Annu. Rev. Immunol. 14, 441-457 (1996).

29 Jacob J, Kelsoe G, Rajewsky K, Weiss U. Intraclonal generation of antibody mutants in germinal centres. Nature 354(6352), 389-392 (1991).

30 Berek C, Berger A, Apel M. Maturation of the immune response in germinal centers. Cell 67(6), 1121-1129 (1991).

31 Matsumoto M, Lo SF, Carruthers CJ et al. Affinity maturation without germinal centres in lymphotoxin- $\alpha$-deficient mice. Nature 382(6590), 462-466 (1996).

32 Tarlinton DM, Smith KG. Dissecting affinity maturation: a model explaining 
selection of antibody-forming cells and memory B cells in the germinal centre. Immunol. Today 21(9), 436-441 (2000).

33 MacLennan IC. Germinal centers. Annu. Rev. Immunol. 12, 117-139 (1994).

34 Allen CDC, Okada T, Tang HL, Cyster JG. Imaging of germinal center selection events during affinity maturation. Science 315(5811), 528-531 (2007).

- Showed for the first time the timing of the interactions of various cells in the germinal center.

35 Hauser AE, Junt T, Mempel TR et al. Definition of germinal-center $B$ cell migration in vivo reveals predominant intrazonal circulation patterns. Immunity 26(5), 655-667 (2007).

- Showed for the first time the timing of the interactions of various cells in the germinal center.

36 Schwickert TA, Lindquist RL, Shakhar G et al. In vivo imaging of germinal centres reveals a dynamic open structure. Nature 446(7131), 83-87 (2007).

- Showed for the first time the timing of the interactions of various cells in the germinal center.

37 Allen CDC, Cyster JG. Follicular dendritic cell networks of primary follicles and germinal centers: phenotype and function. Semin. Immunol. 20(1), 14-25 (2008).

- Comprehensive review of the structure and function of follicular dendritic cells.

38 Ye BH, Cattoretti G, Shen Q et al. The Bcl-6 proto-oncogene controls germinalcentre formation and Th2-type inflammation. Nat. Genet. 16(2), 161-170 (1997).

39 Tew JG, Wu J, Fakher M, Szakal AK, Qin D. Follicular dendritic cells: beyond the necessity of T-cell help. Trends Immunol. 22(7), 361-367 (2001).

40 Franzoso G, Carlson L, Poljak L et al. Mice deficient in nuclear factor (NF) $-\kappa \mathrm{B} / \mathrm{p} 52$ present with defects in humoral responses, germinal center reactions, and splenic microarchitecture. J. Exp. Med. 187(2), 147-159 (1998).

41 Poljak L, Carlson L, Cunningham K, Kosco-Vilbois MH, Siebenlist U. Distinct activities of $\mathrm{p} 52 / \mathrm{NF}-\mathrm{kB}$ required for proper secondary lymphoid organ microarchitecture: functions enhanced by Bcl-3. J. Immunol. 163(12), 6581-6588 (1999).

42 Matsumoto M, Fu YX, Molina $\mathrm{H}$ et al. Distinct roles of lymphotoxin $\alpha$ and the type I tumor necrosis factor (TNF) receptor in the establishment of follicular dendritic cells from non-bone marrowderived cells. J. Exp. Med. 186(12), 1997-2004 (1997).

43 Endres R, Alimzhanov MB, Plitz T et al. Mature follicular dendritic cell networks depend on expression of lymphotoxin $\beta$ receptor by radioresistant stromal cells and of lymphotoxin $\beta$ and tumor necrosis factor by B cells. J. Exp. Med. 189(1), 159-168 (1999).

44 Ansel KM, Ngo VN, Hyman PL et al. A chemokine-driven positive feedback loop organizes lymphoid follicles. Nature 406(6793), 309-314 (2000).

45 Hannum LG, Haberman AM, Anderson SM, Shlomchik MJ. Germinal center initiation, variable gene region hypermutation, and mutant $\mathrm{B}$ cell selection without detectable immune complexes on follicular dendritic cells. J. Exp. Med. 192(7), 931-942 (2000).

46 Rahman ZSM, Rao SP, Kalled SL, Manser T. Normal induction but attenuated progression of germinal center responses in BAFF and BAFF-R signalingdeficient mice. J. Exp. Med. 198(8), 1157-1169 (2003).

47 Phan TG, Green JA, Gray EE, Xu Y, Cyster JG. Immune complex relay by subcapsular sinus macrophages and noncognate B cells drives antibody affinity maturation. Nat. Immunol. 10(7), 786-793 (2009).

- Showed the importance for the germinal center reaction for antigen transport by noncognate $B$ cells.

48 Victoratos P, Lagnel J, Tzima $S$ et al. FDC-specific functions of $\mathrm{p} 55 \mathrm{TNFR}$ and IKK2 in the development of FDC networks and of antibody responses. Immunity 24(1), 65-77 (2006).

49 Randall KL, Lambe T, Johnson A et al. Dock8 mutations cripple B cell immunological synapses, germinal centers and long-lived antibody production. Nat. Immunol. 10(12), 1283-1291 (2009).

50 Phan TG, Grigorova I, Okada T, Cyster JG. Subcapsular encounter and complement-dependent transport of immune complexes by lymph node B cells. Nat. Immunol. 8(9), 992-1000 (2007).

- Illustrated a new mechanism of antigen capture and transport to germinal centers.

51 Al-Qahtani A, Xu Z, Zan H, Walsh CM, Casali P. A role for DRAK2 in the germinal center reaction and the antibody response. Autoimmunity 41(5), 341-352 (2008).
52 Koopman G, Keehnen RM, Lindhout E, Zhou DF, de Groot C, Pals ST. Germinal center B cells rescued from apoptosis by CD40 ligation or attachment to follicular dendritic cells, but not by engagement of surface immunoglobulin or adhesion receptors, become resistant to CD95induced apoptosis. Eur J. Immunol. 27(1), 1-7 (1997).

53 Vinuesa CG, Tangye SG, Moser B, Mackay CR. Follicular B helper T cells in antibody responses and autoimmunity. Nat. Rev. Immunol. 5(11), 853-865 (2005).

- First comprehensive review of the specialized $\mathrm{T}$ cells present in germinal centers.

54 Nurieva RI, Chung Y, Martinez GJ et al. Bcl6 mediates the development of T follicular helper cells. Science 325(5943), 1001-1005 (2009).

- This paper and the next two showed that the Bcl-6 transcription factor essential for germinal center B-cell formation was also important for the specialized T-follicular helper cells (TFHs) of the germinal center.

55 Johnston RJ, Poholek AC, DiToro D et al. Bcl6 and Blimp-1 are reciprocal and antagonistic regulators of $T$ follicular helper cell differentiation. Science 325(5943), 1006-1010 (2009).

- Showed that the Bcl-6 transcription factor essential for germinal center B-cell formation was also important for the specialized TFHs of the germinal center.

56 Yu D, Rao S, Tsai LM et al. The transcriptional repressor Bcl-6 directs $\mathrm{T}$ follicular helper cell lineage commitment. Immunity 31(3), 457-468 (2009).

- Showed that the Bcl-6 transcription factor essential for germinal center B-cell formation was also important for the specialized TFHs of the germinal center.

57 Zotos D, Coquet JM, Zhang Y et al. IL-21 regulates germinal center $B$ cell differentiation and proliferation through a B cell-intrinsic mechanism. J. Exp. Med. 207(2), 365-378 (2010).

58 Linterman MA, Beaton L, Yu D et al. IL-21 acts directly on B cells to regulate Bcl- 6 expression and germinal center responses. J. Exp. Med. 207(2), 353-363 (2010).

59 Smith KG, Light A, O’Reilly LA, Ang SM, Strasser A, Tarlinton D. Bcl-2 transgene expression inhibits apoptosis in the germinal center and reveals differences in 
the selection of memory B cells and bone marrow antibody-forming cells. J. Exp. Med. 191(3), 475-484 (2000).

60 Klein U, Casola S, Cattoretti G et al. Transcription factor IRF4 controls plasma cell differentiation and class-switch recombination. Nat. Immunol. 7(7), 773-782 (2006).

61 Shapiro-Shelef M, Lin K-I, McHeyzer-Williams LJ, Liao J, McHeyzer-Williams MG, Calame K. Blimp-1 is required for the formation of immunoglobulin secreting plasma cells and pre-plasma memory B cells. Immunity 19(4), 607-620 (2003).

62 Shaffer AL, Shapiro-Shelef M, Iwakoshi NN et al. XBP1, downstream of Blimp-1, expands the secretory apparatus and other organelles, and increases protein synthesis in plasma cell differentiation. Immunity 21(1), 81-93 (2004)

63 Allen RC, Armitage RJ, Conley ME et al. CD40 ligand gene defects responsible for X-linked hyper-IgM syndrome. Science 259(5097), 990-993 (1993).

64 Aruffo A, Farrington M, Hollenbaugh D et al. The CD40 ligand, gp39, is defective in activated $T$ cells from patients with X-linked hyper-IgM syndrome. Cell 72(2), 291-300 (1993).

65 DiSanto JP, Bonnefoy JY, Gauchat JF, Fischer A, de Saint Basile G. CD40 ligand mutations in $\mathrm{x}$-linked immunodeficiency with hyper-IgM. Nature 361(6412), 541-543 (1993).

66 Fuleihan R, Ramesh N, Loh R et al. Defective expression of the CD40 ligand in $\mathrm{X}$ chromosome-linked immunoglobulin deficiency with normal or elevated IgM. Proc. Natl Acad. Sci. USA 90(6), 2170-2173 (1993).

67 Ferrari S, Giliani S, Insalaco A et al. Mutations of $C D 40$ gene cause an autosomal recessive form of immunodeficiency with hyper IgM. Proc. Natl Acad. Sci. USA 98(22), 12614-12619 (2001).

68 Coffey AJ, Brooksbank RA, Brandau O et al. Host response to EBV infection in X-linked lymphoproliferative disease results from mutations in an $\mathrm{SH} 2$-domain encoding gene. Nat. Genet. 20(2), 129-135 (1998).

69 Nichols KE, Harkin DP, Levitz S et al. Inactivating mutations in an $\mathrm{SH} 2$ domain-encoding gene in X-linked lymphoproliferative syndrome. Proc. Natl Acad. Sci. USA 95(23), 13765-13770 (1998).
70 Sayos J, Wu C, Morra M et al. The $\mathrm{X}$-linked lymphoproliferative-disease gene product SAP regulates signals induced through the co-receptor SLAM. Nature 395(6701), 462-469 (1998).

71 Crotty S, Kersh EN, Cannons J, Schwartzberg PL, Ahmed R. SAP is required for generating long-term humoral immunity. Nature 421(6920), 282-287 (2003).

72 Qi H, Cannons JL, Klauschen F, Schwartzberg PL, Germain RN. SAPcontrolled T-B cell interactions underlie germinal centre formation. Nature 455(7214), 764-769 (2008).

73 Nichols KE, Ma CS, Cannons JL, Schwartzberg PL, Tangye SG. Molecular and cellular pathogenesis of X-linked lymphoproliferative disease. Immunol. Rev. 203, 180-199 (2005).

74 Ma CS, Nichols KE, Tangye SG. Regulation of cellular and humoral immune responses by the SLAM and SAP families of molecules. Annu. Rev. Immunol. 25, 337-379 (2007).

75 Bacchelli C, Buckridge S, Thrasher AJ, Gaspar HB. Translational mini-review series on immunodeficiency: molecular defects in common variable immunodeficiency. Clin. Exp. Immunol. 149(3), 401-409 (2007).

76 Grimbacher B, Hutloff A, Schlesier M et al. Homozygous loss of ICOS is associated with adult-onset common variable immunodeficiency. Nat. Immunol. 4(3), 261-268 (2003)

- First genetic cause of common variable immune deficiency to be identified.

77 Warnatz K, Bossaller L, Salzer U et al. Human ICOS deficiency abrogates the germinal center reaction and provides a monogenic model for common variable immunodeficiency. Blood 107(8), 3045-3052 (2006).

78 Wong S-C, Oh E, Ng C-H, Lam K-P. Impaired germinal center formation and recall T-cell-dependent immune responses in mice lacking the costimulatory ligand B7-H2. Blood 102(4), 1381-1388 (2003).

79 van Zelm MC, Reisli I, van der Burg M et al. An antibody-deficiency syndrome due to mutations in the $C D 19$ gene. N. Engl. J. Med 354(18), 1901-1912 (2006).

80 Wang Y, Brooks SR, Li X, Anzelon AN, Rickert RC, Carter RH. The physiologic role of $\mathrm{CD} 19$ cytoplasmic tyrosines. Immunity 17(4), 501-514 (2002).

81 van Zelm MC, Smet J, Adams B et al. CD81 gene defect in humans disrupts
CD19 complex formation and leads to antibody deficiency. J. Clin. Invest. 120(4), 1265-1274 (2010).

82 Mackay F, Schneider P, Rennert P, Browning J. Baff and April: a tutorial on B cell survival. Annu. Rev. Immunol. 21, 231-264 (2003).

83 Salzer U, Chapel HM, Webster ADB et al. Mutations in TNFRSF13B encoding TACI are associated with common variable immunodeficiency in humans. Nat. Genet. 37(8), 820-828 (2005).

84 Castigli E, Wilson SA, Garibyan L et al. TACI is mutant in common variable immunodeficiency and IgA deficiency. Nat. Genet. 37(8), 829-834 (2005).

85 Pan-Hammarstrom Q, Salzer U, Du L et al. Reexamining the role of TACI coding variants in common variable immunodeficiency and selective $\operatorname{Ig} \mathrm{A}$ deficiency. Nat. Genet. 39(4), 429-430 (2007).

86 Yan M, Wang H, Chan B et al. Activation and accumulation of $\mathrm{B}$ cells in TACIdeficient mice. Nat. Immunol. 2(7), 638-643 (2001).

87 Warnatz K, Salzer U, Rizzi M et al. $\mathrm{B}$-cell activating factor receptor deficiency is associated with an adult-onset antibody deficiency syndrome in humans. Proc. Natl Acad. Sci. USA 106(33), 13945-13950 (2009).

88 Zheng B, Switzer K, Marinova E, Wansley D, Han S. Correction of age-associated deficiency in germinal center response by immunization with immune complexes. Clin. Immunol. 124(2), 131-137 (2007)

89 Rush CM, Mitchell TJ, Burke B, Garside P. Dissecting the components of the humoral immune response elicited by DNA vaccines. Vaccine 24(6), 776-784 (2006).

90 Ma Y, Ross AC. Toll-like receptor 3 ligand and retinoic acid enhance germinal center formation and increase the tetanus toxoid vaccine response. Clin. Vaccine Immunol. 16(10), 1476-1484 (2009).

91 Lee $\mathrm{CH}$, Melchers M, Wang $\mathrm{H}$ et al. Regulation of the germinal center gene program by interferon (IFN) regulatory factor $8 /$ IFN consensus sequence-binding protein. J. Exp. Med. 203(1), 63-72 (2006). (Erratum appears in J. Exp. Med. 203(2), 475 [2006]).

92 Schubart K, Massa S, Schubart D, Corcoran LM, Rolink AG, Matthias P. $B$ cell development and immunoglobulin gene transcription in the absence of Oct-2 
and OBF-1. Nat. Immunol. 2(1), 69-74

(2001) (Erratum appears in Nat. Immunol. 7(9), 1004 [2006]).

93 Huntington ND, Xu Y, Puthalakath H et al. CD 45 links the B cell receptor with cell survival and is required for the persistence of germinal centers. Nat. Immunol. 7(2), 190-198 (2006).

94 Clayton E, Bardi G, Bell SE et al. A Crucial role for the $110\{\delta\}$ subunit of phosphatidylinositol 3-kinase in B cell development and activation. J. Exp. Med. 196, 753-763 (2002).

95 Otero DC, Rickert RC. CD19 function in early and late B cell development. II. CD19 facilitates the pro- $\mathrm{B} /$ pre- $\mathrm{B}$ transition. J. Immunol. 171(11), 5921-5930 (2003).

96 Quemeneur L, Angeli V, Chopin M, Jessberger R. SWAP-70 deficiency causes high-affinity plasma cell generation despite impaired germinal center formation. Blood 111(5), 2714-2724 (2008).

97 Su GH, Chen HM, Muthusamy N et al. Defective B cell receptor-mediated responses in mice lacking the Ets protein, Spi-B. EMBO J. 16(23), 7118-7129 (1997).

98 Delgado P, Cubelos B, Calleja E et al. Essential function for the GTPase TC21 in homeostatic antigen receptor signaling. Nat. Immunol. 10(8), 880-888 (2009).
99 Ferguson SE, Han S, Kelsoe G, Thompson CB. CD28 is required for germinal center formation. J. Immunol. 156(12), 4576-4581 (1996).

100 Borriello F, Sethna MP, Boyd SD et al. B7-1 and B7-2 have overlapping, critical roles in immunoglobulin class switching and germinal center formation. Immunity 6(3), 303-313 (1997).

101 Cunningham AF, Serre K, Mohr E, Khan M, Toellner K-M. Loss of CD154 impairs the Th2 extrafollicular plasma cell response but not early $\mathrm{T}$ cell proliferation and interleukin-4 induction. Immunology 113(2), 187-193 (2004).

102 Kawabe T, Naka T, Yoshida K et al. The immune responses in CD40-deficient mice: impaired immunoglobulin class switching and germinal center formation. Immunity 1(3), 167-178 (1994).

103 Cannons JL, Qi H, Lu KT et al. Optimal germinal center responses require a multistage $T$ cell: $B$ cell adhesion process involving integrins, SLAM-associated protein, and CD84. Immunity 32(2), 253-265 (2010).

104 Caamano JH, Rizzo CA, Durham SK et al.

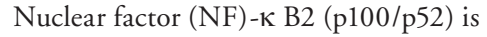
required for normal splenic microarchitecture and B cell-mediated immune responses. J. Exp. Med. 187(2), 185-196 (1998).
105 Weih DS, Yilmaz ZB, Weih F. Essential role of RelB in germinal center and marginal zone formation and proper expression of homing chemokines. J. Immunol. 167(4), 1909-1919 (2001).

106 Vora KA, Tumas-Brundage KM, Lentz VM, Cranston A, Fishel R, Manser T. Severe attenuation of the B cell immune response in Msh2-deficient mice. J. Exp. Med. 189(3), 471-482 (1999).

107 Kuwahara K, Fujimura S, Takahashi Y et al. Germinal center-associated nuclear protein contributes to affinity maturation of $\mathrm{B}$ cell antigen receptor in T celldependent responses. Proc. Natl Acad. Sci. USA 101(4), 1010-1015 (2004).

108 Thai T-H, Calado DP, Casola S et al. Regulation of the germinal center response by microRNA-155. Science 316(5824), 604-608 (2007).

\section{Website}

201 Panum PL. Observations made during the epidemic of measles on the Faroe Islands in the year 1846 (translated from Danish). (Delta Omega Honorary Society in Public Health, 1847) www.deltaomega.org/Classics.cfm 